ARTICLE

\title{
Laser-driven growth of structurally defined transition metal oxide nanocrystals on carbon nitride photoelectrodes in milliseconds
}

Junfang Zhang 1,2, Yajun Zou', Stephan Eickelmann (10 1, Christian Njel ${ }^{3}$, Tobias Heil (10 1, Sebastian Ronneberger ${ }^{1}$, Volker Strauss ${ }^{1}$, Peter H. Seeberger ${ }^{1,2}$, Aleksandr Savateev $\mathbb{B}^{1}$ \& Felix F. Loeffler (i) ${ }^{1 凶}$

Fabrication of hybrid photoelectrodes on a subsecond timescale with low energy consumption and possessing high photocurrent densities remains a centerpiece for successful implementation of photoelectrocatalytic synthesis of fuels and value-added chemicals. Here, we introduce a laser-driven technology to print sensitizers with desired morphologies and layer thickness onto different substrates, such as glass, carbon, or carbon nitride (CN). The specially designed process uses a thin polymer reactor impregnated with transition metal salts, confining the growth of transition metal oxide (TMO) nanostructures on the interface in milliseconds, while their morphology can be tuned by the laser. Multiple nano-p-n junctions at the interface increase the electron/hole lifetime by efficient charge trapping. A hybrid copper oxide/CN photoanode with optimal architecture reaches 10 times higher photocurrents than the pristine $\mathrm{CN}$ photoanode. This technology provides a modular approach to build a library of TMO-based composite films, enabling the creation of materials for diverse applications.

\footnotetext{
${ }^{1}$ Max Planck Institute of Colloids and Interfaces, Potsdam, Germany. ${ }^{2}$ Department of Chemistry and Biochemistry, Freie Universität Berlin, Berlin, Germany ${ }^{3}$ Institute for Applied Materials (IAM) and Karlsruhe Nano Micro Facility (KNMF), Karlsruhe Institute of Technology (KIT), Eggenstein-

Leopoldshafen, Germany. ${ }^{凶}$ email: Felix.Loeffler@mpikg.mpg.de
} 
C onversion of abundant solar energy into fuels and valueadded chemicals in photoelectrochemical cells received enormous attention as a technology capable of easing the environmental impact ${ }^{1}$. Successful implementation of this conversion requires durable, inexpensive photoelectrodes enabling high photocurrents and low overpotentials. As a cost-efficient and sustainable semiconductor, polymeric carbon nitride $(\mathrm{CN})$ is a promising material to fulfill such requirements ${ }^{2,3}$. The main challenges of using CNs in photoelectrochemistry are poor electron mobility and fast charge recombination, which have limited broad application ${ }^{4,5}$.

Forming heterojunctions with other materials, such as transition metal oxides (TMOs), is reported as an efficient solution for charge seperation $^{5-7}$. For example, the incorporation of copper oxide $(\mathrm{CuO})$ into the $\mathrm{CN}$ matrix induces electron delocalization to increase electron mobility in the composite material ${ }^{8}$. At the same time, $\mathrm{CuO}$ with a narrow bandgap $(\sim 1.4 \mathrm{eV})$ can sensitize $\mathrm{CN}$ ( $\sim 2.7 \mathrm{eV}$ bandgap) to harvest larger portions of the solar spectrum $^{9}$. A variety of $\mathrm{CuO} / \mathrm{CN}$ composites have been applied in different fields, such as anode materials for lithium-ion batteries $^{10}$, photocatalysts for the decomposition of organic pollutants $^{11}$, or voltammetric sensors for the detection of glucose $^{12}$.

Significant efforts have been devoted to the development of synthetic procedures for the preparation of TMO/CN composite materials, including copolymerization ${ }^{13,14}$, photodeposition ${ }^{15}$, microwave-assisted $^{16}$, and hydrothermal methods ${ }^{17,18}$. These processes yield well-defined structures during bulk synthesis of the materials, but they are not suitable for the fabrication of composite films with diverse micro-/nanostructures. Moreover, the most common method, (hydro)thermal treatment, requires a high input of thermal power and long processing times ${ }^{19}$. Even though a physical $\mathrm{CN}$ sputtering method has been introduced to generate TMO/CN films with precisely controlled composition, this method shows large interlayer distances with limited interaction and charge transport ${ }^{20}$. The introduction of additional components, such as graphene, aims to improve the performance, nevertheless, results in inefficient systems ${ }^{21-23}$. The abovementioned issues are responsible for the underperformance of these films in photoelectric semiconductor devices. Therefore, a flexible and modular strategy is required to generate micro-/ nano-organized composite films.

We developed the laser-driven transfer synthesis (LTRAS) technology from the laser-induced forward transfer (LIFT) principle. Unlike the traditional (pulsed) laser ablation methods, which usually release the synthesized particles into liquids ${ }^{24}$, LIFT is a versatile maskless method for the transfer of thin-film surface patterns. It is realized in a wide range of variations, for depositing precise and minute amounts of almost any material onto surfaces $^{25}$. For example, metals can be transferred by direct laser melting and ejection, using high-power pulsed lasers ${ }^{26}$. A notable variant using pulsed lasers, called matrix-assisted pulsed laser evaporation direct-write (MAPLE DW) ${ }^{27}$, enables the transfer of thermally and mechanically sensitive materials, such as (nano) particles (e.g., ceramics, alloys, polymers). In addition, also bacteria $^{28}$ or biomolecules ${ }^{29-31}$ can be transferred, by introducing a sacrificial polymer ${ }^{32}$ or laser absorber, enabling more gentle modes of transfer, via ejection, blister (blister-actuated LIFT) and jet formation, or direct contact ${ }^{33,34}$. However, all these existing techniques, including our own previous works, are mainly focused on the transfer of materials instead of in situ synthesis of materials.

Here, we show that our continuous wave laser process cannot only transfer but, at the same time, also drive a chemical reaction to generate precisely controlled materials at the interface of different substrates (e.g., glass, fluorine-doped tin oxide (FTO), carbon, $\mathrm{CN}$ ). In the laser system, the configuration of the composite film can be flexibly tuned in terms of macroscopic location on the substrate (by the laser irradiation pattern), microscopic particle shape and size (e.g., by laser energy), as well as the types of materials (by different precursor materials or sequential deposition of several precursors). We use the LTRAS method to generate $\mathrm{CuO} / \mathrm{CN}$ composite films as photoanodes. Thin-layer $\mathrm{CuO}$ nanostructures with controllable size and shape are obtained on the CN substrate. Nano-structured p-n junctions are created due to the spatial organization of the composite layers. The $\mathrm{CuO}$ morphology significantly influences charge transport and distributions in the films, which further changes the efficiency of photogenerated charge separation and transfer. The photocurrent of the synthetic $\mathrm{CuO} / \mathrm{CN}$ photoanodes induced under white light is up to ten times higher than the photocurrent of the photoanode made of $\mathrm{CN}$ only in $0.1 \mathrm{M} \mathrm{NaOH}$ solution. The incident photonto-electron conversion efficiency (IPCE) values of $\mathrm{CuO} / \mathrm{CN}$ at 415 and $455 \mathrm{~nm}$ reach up to $11.46 \%$ and $3.41 \%$, respectively. These composite electrodes are used as non-enzymatic biosensors for glucose under ultra-low operation potential of $0.1 \mathrm{~V}$ (vs. Ag/AgCl reference electrode) and irradiation with visible light. Furthermore, the LTRAS method is not limited to Cu-salts-other TMO nanostructures, such as $\mathrm{CoO}$ and $\mathrm{NiO}$ on the $\mathrm{CN}$ film, are readily available via this rapid synthesis procedure.

\section{Results and discussion}

Establishing the laser-driven transfer and synthesis method. LTRAS is based on the photothermic effect: focused laser irradiation generates a confined temperature field at the desired position $^{35}$. Precursor salts are transferred inside the melted polymer and converted into metal oxide nanoparticles within milliseconds (Fig. 1). In general, this process requires a donor and acceptor surface. A homogenous $\mathrm{CN}$ film of $300-500 \mathrm{~nm}$ thickness was generated on an FTO glass slide by vapor deposition polymerization (VDP) 36,37 to prepare the "acceptor slide" (Supplementary Fig. 1). A "donor slide" was prepared by spin-coating a solution of metal precursor (first, we used $\left.\mathrm{Cu}\left(\mathrm{NO}_{3}\right)_{2} \cdot 3 \mathrm{H}_{2} \mathrm{O}\right)$ and styrene-acrylic copolymer (S-LEC) onto the surface of a glass slide, bearing a polyimide film (Supplementary Fig. 2). To transfer the metal precursor onto the $\mathrm{CN}$ substrate, we placed the donor slide on top of the acceptor slide and irradiated the donor slide with a laser setup (Supplementary Figs. 3 and 4). As the light passes through the donor glass slide it is absorbed by the polyimide layer, which converts light into thermal energy. Thereby, the copolymer with the embedded metal precursor is melted and transferred in a direct contact mechanism to the acceptor slide, as we have reported earlier ${ }^{34}$. This step can be repeated many times with different donor slides, such that the thickness of the transferred layer can be easily adjusted. In addition, the LTRAS process shows successful transfer even on an ultrathin $\mathrm{CN}$ film with a thickness of around $50 \mathrm{~nm}$ (Supplementary Fig. 5), which proves this method is not limited by the thickness of the $\mathrm{CN}$ film on the acceptor slide.

Scanning electron microscopy (SEM) imaging of the acceptor slide after transfer reveals star-like structures (Fig. 2a). Further analysis using energy-dispersive X-ray spectroscopy (EDX) indicates that these structures consist of copper and oxygen, while carbon and nitrogen are observed only within the $\mathrm{CN}$ substrate.

To investigate the oxidation states of copper, X-ray photoelectron spectroscopy (XPS) was performed on the composite films. The full scan spectrum (Supplementary Fig. 6a) shows characteristic peaks of all elements: $\mathrm{C}, \mathrm{N}, \mathrm{Cu}$, and $\mathrm{O}$ from the composite material and $\mathrm{Si}$ from the glass substrate, which is consistent with the EDX mapping results. The $\mathrm{Cu} 2 p$ spectrum is normally 
a

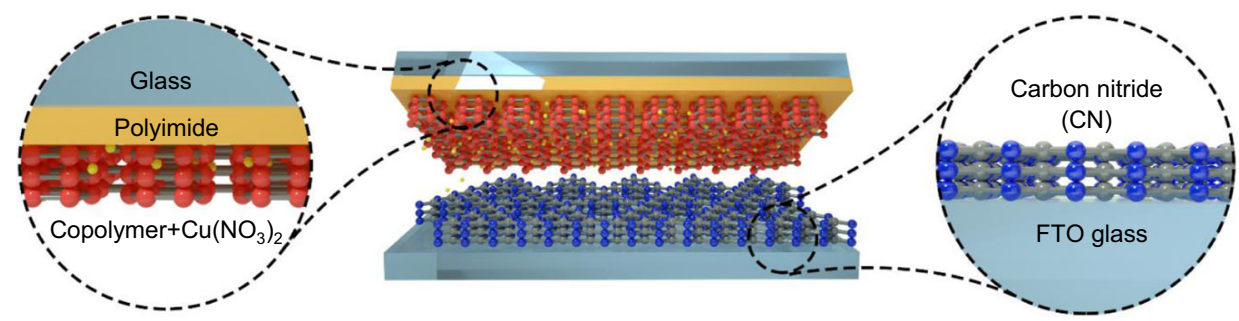

b
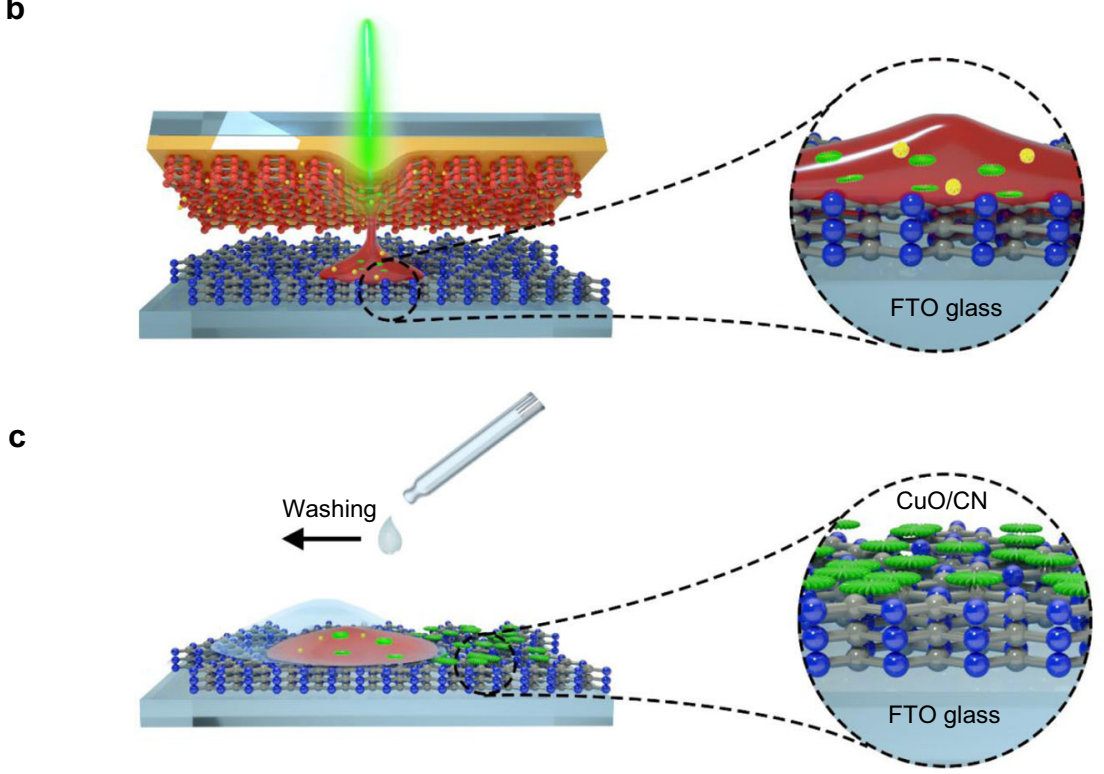

Fig. 1 Principle of the laser-driven transfer synthesis (LTRAS) process for the generation of structurally defined transition metal oxide/carbon nitride (TMO/CN) composite films. a Laser irradiation transfers material from a donor to an acceptor surface. The donor slide is prepared by spin coating a mixture of dissolved copolymer together with transition metal (TM) precursor onto a polyimide-coated glass slide. The acceptor slide is prepared by vapor deposition polymerization of CN onto a fluorine-doped tin oxide (FTO) glass slide. $\mathbf{b}$ The laser rapidly heats, melts, and transfers the donor material. At the same time, the decomposition temperature of the metal precursor is reached and TMO structures are formed. c After a short rinsing with acetone, the $\mathrm{TMO} / \mathrm{CN}$ composite film is ready.

composed of the $2 p_{3 / 2}-2 p_{1 / 2}$ doublet, separated by $20 \mathrm{eV}$ with a $2: 1$ intensity ratio due to spin-orbit coupling. Here, only the $\mathrm{Cu}$ $2 p_{3 / 2}$ peaks are considered for the copper chemical states. The peak $\mathrm{Cu} 2 p_{3 / 2}$ located at $934.5 \mathrm{eV}$ with its shake-up satellites is a signature of various $\mathrm{Cu}(+\mathrm{II})$ species, such as $\mathrm{CuO}$ and $\mathrm{Cu}\left(\mathrm{NO}_{3}\right)_{2}$ (Fig. 2b). Based on the presence of a nitrogen peak around 407 $\mathrm{eV}$, corresponding to the nitrate compound (Supplementary Fig. 6c), the copper detected on the surface of the $\mathrm{CuO} / \mathrm{CN}$ composite corresponds to a mixture of $\mathrm{CuO}$ and $\mathrm{Cu}\left(\mathrm{NO}_{3}\right)_{2}$. The small $\mathrm{Cu} 2 p_{3 / 2}$ peak at the low binding energy corresponds to the reduction product of $\mathrm{Cu}(+\mathrm{II})$ under XPS analysis ${ }^{38}$. For the Xray powder diffraction pattern (XRD, Fig. 2c) of the composite films, the additional peaks at $35.5,38.6$, and 48.7 can be assigned to the (111), (002), and (202) facets in the monoclinic phase of $\mathrm{CuO}$ (JCPDS no.48-1548) respectively.

These results indicate that during the LTRAS process, we not only transferred metal precursors onto the $\mathrm{CN}$ film but also covered cupric nitrate to defined $\mathrm{CuO}$ (Fig. 2d). To further investigate the $\mathrm{CuO}-\mathrm{CN}$ interaction, we peeled off several $\mathrm{CuO}$ / $\mathrm{CN}$ films from acceptor slides after laser transfer and put the films into water. We stirred the solution overnight and treated it with ultrasound for $3 \mathrm{~h}$ to try to separate the $\mathrm{CuO}$ from the $\mathrm{CN}$ layer. However, in TEM, we could hardly find single $\mathrm{CuO}$ particles, which confirms the high affinity of $\mathrm{CuO}$ to $\mathrm{CN}$ and proves that the composite is quite stable. This affinity is likely caused by the coordinate bonding of the partially occupied $\mathrm{Cu}-3 \mathrm{~d}$ shell and neighboring $\mathrm{N}$ regions of the $\mathrm{CN}^{39,40}$.

Conventionally, the synthesis of $\mathrm{CuO}$ is conducted in furnaces at $100-500^{\circ} \mathrm{C}$ for $0.5-36 \mathrm{~h}$ (Supplementary Table 1 ), employing either hydrothermal or thermal decomposition methods ${ }^{41-45}$. In contrast, the synthesis proceeds within milliseconds with the LTRAS method (Supplementary Fig. 7). The focused laser irradiation results in high energetic efficiency by rapid heating at the desired position. As we have reported recently ${ }^{46}$, the thermal map of a $50 \mathrm{~ms}$ laser irradiation spot (Fig. 3a) on a donor slide features $>500^{\circ} \mathrm{C}$ in the spot center. The donor film area, which surpasses the melting temperature of the copolymer $\left(210^{\circ}\right.$ C) ${ }^{46}$, is efficiently transferred to the acceptor slide. The melting temperature of S-LEC $\left(210^{\circ} \mathrm{C}\right.$, blue circle) is higher than the decomposition temperature of $\mathrm{Cu}\left(\mathrm{NO}_{3}\right)_{2}\left(170^{\circ} \mathrm{C}\right)$, indicating that $\mathrm{CuO}$ is the predominant product in the transferred area. The thermal profiles (Fig. 3b) show that longer irradiation times can not only induce higher temperatures but also increase the melting area. Therefore, more material is transferred upon longer irradiation times (see Supplementary Fig. 4 and the following description for a detailed calculation of effective irradiation times).

Besides irradiation time, the synthesis process can also be influenced by the laser wavelength (here 405 or $488 \mathrm{~nm}$ ), due to higher absorption at shorter wavelengths by the polyimide 
a
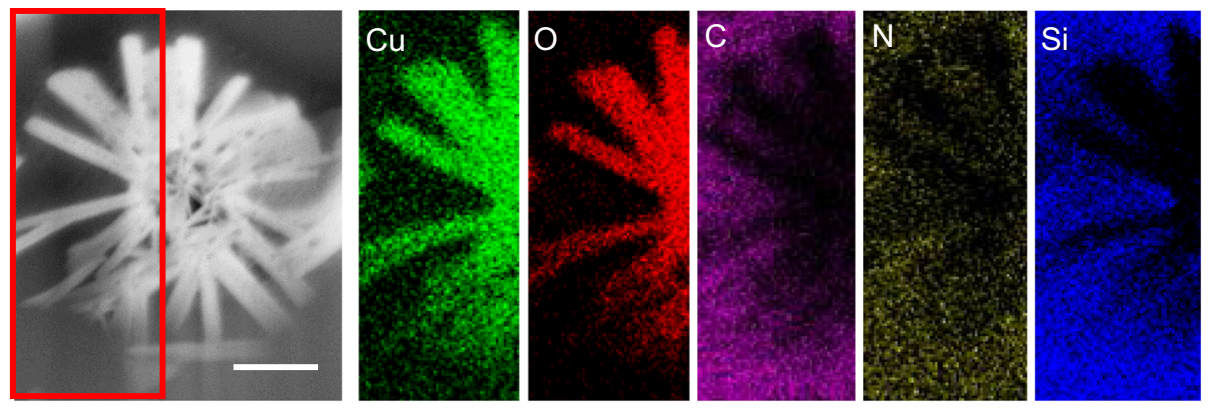

b
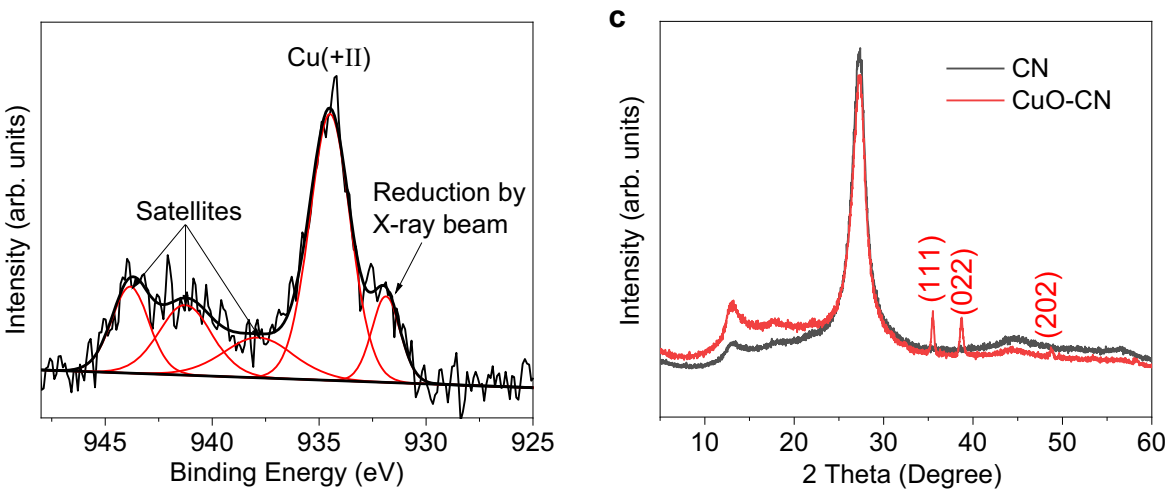

d

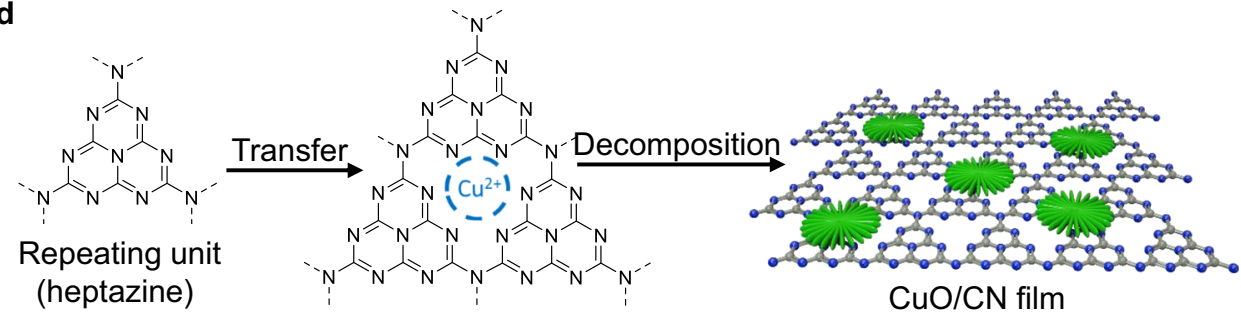

Fig. 2 Characterization of the CuO/carbon nitride (CN) composite material generated by LTRAS. a SEM image and EDX elemental maps of the transferred composite material (scale bar $2 \mu \mathrm{m}$ ). b High-resolution XPS binding energy spectrum of $\mathrm{Cu} 2 p$. c XRD spectrum of CN and CuO/CN composite films. d Schematic illustration of the synthetic route during the transfer process.

(Fig. 3c). At $405 \mathrm{~nm}$, the absorption of polyimide is around five times higher than at $488 \mathrm{~nm}$, causing a higher temperature and more material to be transferred. The thickness of the transferred material was measured by vertical scanning interferometry (VSI, Fig. 3d). Gradients with different effective laser power densities

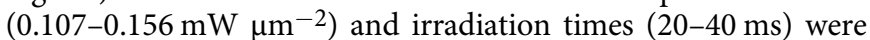
generated (Supplementary Fig. 8). In comparison to the diameters of the spots that are around $150 \mu \mathrm{m}$, their thickness is in the nanometer regime. Even with the higher laser power density of

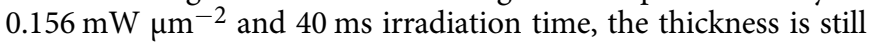
below $60 \mathrm{~nm}$. During the transfer, the melted copolymer serves as a nanoscale reactor for the generation of $\mathrm{CuO}$ nanocrystals. The design of this polymer reactor restricts the growth of $\mathrm{CuO}$ in the axial direction that preferentially results in confined $2 \mathrm{D}$ structures, attached to the $\mathrm{CN}$ surface.

Facile control of nanocrystal morphology. Rod-like, star-like, and rhombic structures were obtained via LTRAS with sizes ranging from $\sim 200 \mathrm{~nm}$ to $\sim 5 \mu \mathrm{m}$ (Fig. 4). Length/size control was achieved by changing the concentration of the metal precursor in the polymer mixture of the donor slide. When we decreased the concentration of $\mathrm{Cu}\left(\mathrm{NO}_{3}\right)_{2}$ from $300 \mu \mathrm{M}$ to $100 \mu \mathrm{M}$, the size of the $\mathrm{CuO}$ rods (Fig. 4i-k) decreased from $450 \mathrm{~nm}$ to $200 \mathrm{~nm}$. Moreover, irradiation time and laser power influence the shape of the $\mathrm{CuO}$ structures. A fast scanning speed $\left(60 \mu \mathrm{m} \mathrm{ms}^{-1}\right)$ and relatively low laser power density $\left(0.132 \mathrm{~mW} \mathrm{\mu m}^{-2}\right)$ form nanorods (Fig. $4 \mathrm{i}-\mathrm{k})$, whereas slower scanning $\left(35 \mu \mathrm{m} \mathrm{ms} \mathrm{m}^{-1}\right)$ or

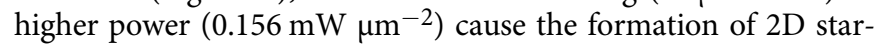
shaped structures (Fig. 4l, n, p).

Upon heating of the polymer and precursor mixture by the laser (Supplementary Fig. 9), the polymer melts, increasing its solubility. Since slower scanning speed causes longer irradiation time, more precursor is transferred and more $\mathrm{CuO}$ nanocrystals are generated. When the laser is switched off, the polymer begins to solidify again. Due to this phase change, the solubility drastically decreases, forcing the growth of larger $\mathrm{CuO}$ nanocrystals. The nanocrystals attach to the same facets of the crystallization seeds. Assuming a higher concentration of $\mathrm{CuO}$ nanocrystals in the mixture at a slower scanning speed, the probability of faults, i.e., attachment of the nanocrystal to a wrong facet, is higher, thus under such conditions star-like nanostructures are formed. On the other hand, faster-scanning speed, and therefore shorter irradiation time, produces fewer $\mathrm{CuO}$ nanocrystals that attach exclusively along the [010] $\mathrm{CuO}$ lattice fringe, giving rise to nanorods (Supplementary Fig. 10).

As mentioned before, the laser wavelength can influence the nanostructure shape as well. For a $405 \mathrm{~nm}$ laser, significantly less power is required due to the high absorption of polyimide at this wavelength. Here, with an effective laser power density of 0.036 $\mathrm{mW} \mu \mathrm{m}^{-2}$ and a speed of $16.7 \mu \mathrm{m} \mathrm{ms}^{-1}$ (about 2-4 times slower than in the $488 \mathrm{~nm}$ system), large amounts of material were 

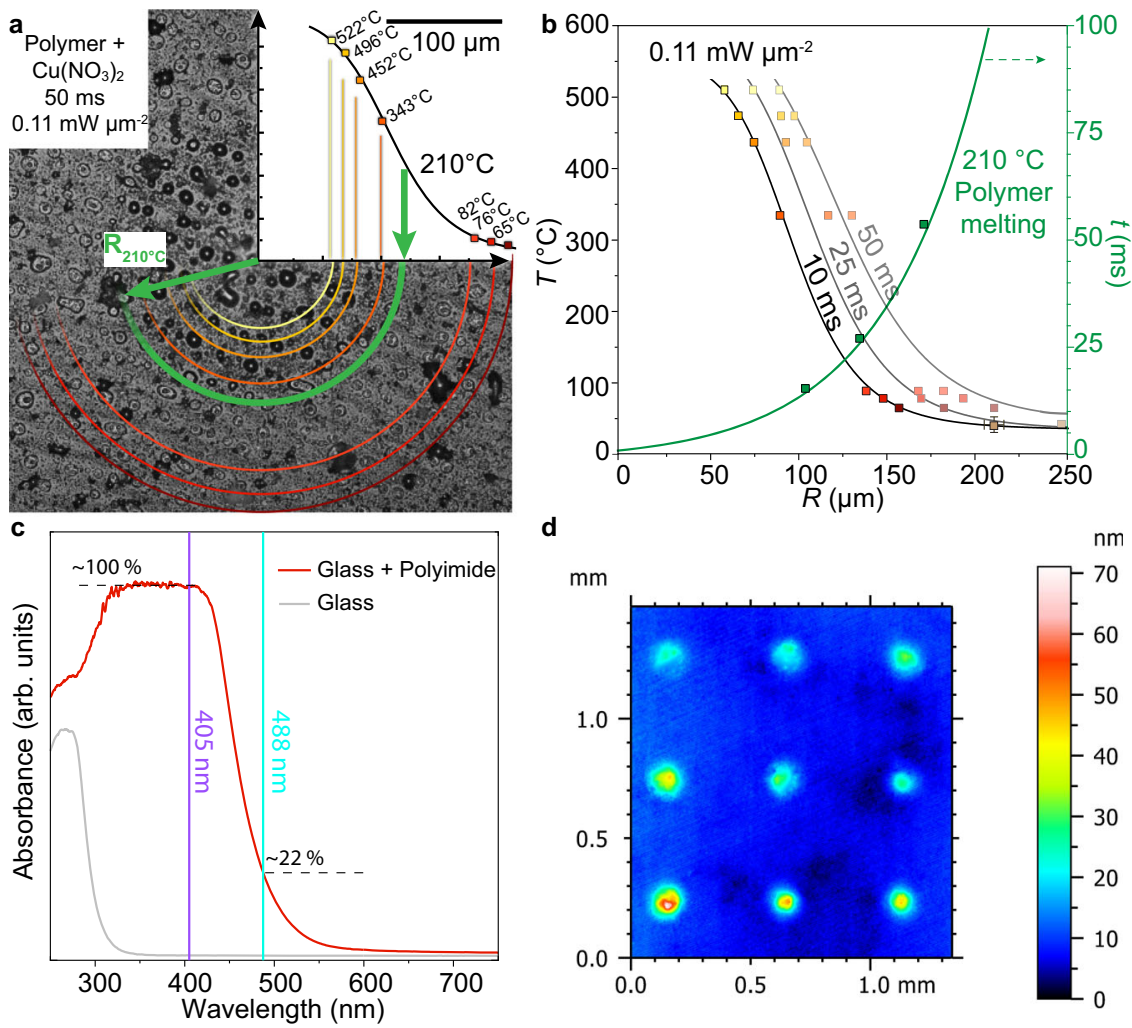

Fig. 3 Thermal characterization of the laser process. a Thermal map of a spot on a donor slide after 50 ms laser irradiation. Colored rings represent the overlay of isotherms. b Thermal profiles for different irradiation times and the radius of melting isotherm (green curve). c UV-VIS spectra of glass and polyimide-covered glass. d Vertical scanning interferometry (VSI) measurement of laser-transferred material spots in a gradient pattern (effective power

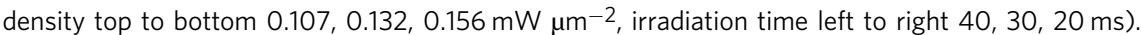

transferred to form $\mathrm{CuO}$ nanorhombi (Fig. 4b, e). In this case, $\mathrm{CuO}$ nanostructures even pile up and form multilayers (Fig. $4 \mathrm{~b}$ ), while at $488 \mathrm{~nm}$, all structures are thin-layer. It should be noted that laser power densities above $0.060 \mathrm{~mW} \mathrm{\mu m}^{-2}$ at $405 \mathrm{~nm}$ destroy the polyimide layer.

LTRAS is not limited to the ultrafast synthesis of $\mathrm{CuO}$ nanostructures but was used to synthesize other TMOs, such as $\mathrm{NiO}$ (Fig. 4c, f) and $\mathrm{CoO}$ (Fig. 4d, g). After laser transfer, the materials on the acceptor slide were characterized by XRD (Supplementary Fig. 11) and EDX mapping (Supplementary Fig. 12). Rod-like $\mathrm{NiO}$ was obtained from $\mathrm{Ni}\left(\mathrm{NO}_{3}\right)_{2}$ at $405 \mathrm{~nm}$ laser irradiation (Fig. 4c). When we increased the effective laser power density from $0.036 \mathrm{~mW} \mu \mathrm{m}^{-2}$ to $0.060 \mathrm{~mW} \mu \mathrm{m}^{-2}$, these $\mathrm{NiO}$ rods formed star-like nanostructures (Fig. $4 \mathrm{f}$ ). In the case of cobalt, laser irradiation converts cobalt nitrate into oxide nanostructures of defined shapes. The $\mathrm{CoO}$ nanospheres observed by SEM are around $160 \mathrm{~nm}$ in diameter (Fig. 4d). Higher power induces a completely different shape of planar $\mathrm{CoO}$ assemblies (Fig. 4g), illustrating the potential of this technology for morphology control.

So far, LTRAS offers a flexible way to grow different TMOs structures on $\mathrm{CN}$ films. In fact, this method is also compatible with other substrates, for example, bare glass, FTO glass, and carbon-coated glass (Supplementary Figs. 13-15). In addition, the transferred polymer significantly influences the growth process. We changed the transferred polymer on the donor slides from SLEC to polyvinylpyrrolidone (PVP), which also offers high reproducibility and accuracy (Supplementary Fig. 16). However, the morphology of the synthesized material is quite different: instead of particles distributed in the transferred polymer phase, a continuous and macroporous layer is formed with the PVP-based donor slides (Supplementary Fig. 17). This allows for an additional degree of flexibility in the LTRAS method, enabling the synthesis of different structures.

Composite photoanodes by LTRAS. The photoluminescence (PL) measurements of pure $\mathrm{CN}$ and $\mathrm{CuO} / \mathrm{CN}$ composite photoelectrodes at room temperature and upon excitation at $365 \mathrm{~nm}$ (Fig. 5b) reveal a significant quenching of the PL intensity after deposition of $\mathrm{CuO}$ onto the electrodes. This indicates the presence of new deactivation paths, such as charge separation between $\mathrm{CN}$ and $\mathrm{CuO}$. As the only composite electrode with a multi-layer $\mathrm{CuO}$ structure, $\mathrm{CuO}_{\mathrm{R} 3} / \mathrm{CN}$ gave a higher PL intensity than the other structures. Thus, charge migration and separation ability in multi-layer structures seem to be limited.

In addition, the shape and size of $\mathrm{CuO}$ nanostructures also influence the performance of the as-synthesized electrodes. Photocurrents of different electrodes under linearly increasing operation potential were measured in $0.1 \mathrm{M} \mathrm{NaOH}$ solution (Fig. 5c). All composite electrodes show higher photocurrent under white light irradiation compared to the pristine $\mathrm{CN}$ electrode, especially the electrodes with thin-layer $\mathrm{CuO}$ structures, which is a result of higher accessibility of the $\mathrm{CN}$ surface to incident photons (Fig. 5d). Star-shaped $\mathrm{CuO}$ with a smaller size $\left(\mathrm{CuO}_{\mathrm{F} 1} / \mathrm{CN}\right)$ exhibits the largest photocurrent density $\left(172 \mu \mathrm{A} \mathrm{cm}^{-2}\right.$ at $1.23 \mathrm{~V}$ vs. reversible hydrogen electrode (RHE)), which is about nine times higher than the pristine $\mathrm{CN}$ electrode and comparable or higher than several other works (Supplementary Table 2). It has been observed that crystal orientations show different reactivity ${ }^{47}$. Therefore, the overall reactivity can be influenced by the particle shape ${ }^{48}$. Star-like $\mathrm{CuO} / \mathrm{CN}$ electrodes yield higher current densities in comparison to those with rod-like structures. This might be caused by the difference in crystal orientation in these two 


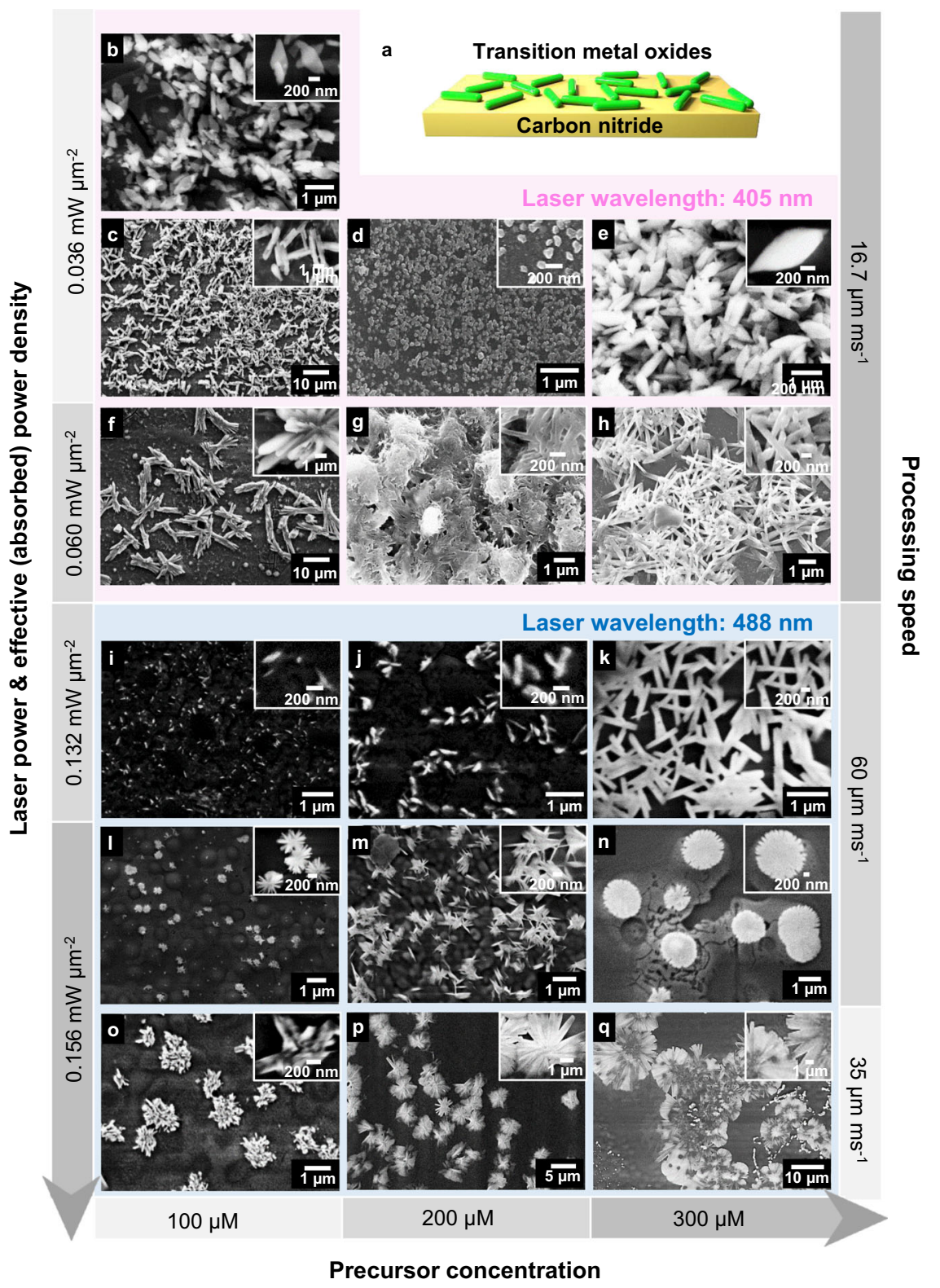

Fig. 4 SEM images of transition metal oxide (TMO) structures synthesized by LTRAS and their corresponding synthesis parameters. a Structure of $\mathrm{TMO} / \mathrm{CN}$ composite films. b, e, h-q $\mathrm{CuO} / \mathrm{CN}$. c, f NiO/CN. d, g CoO/CN.

structures. When we add a known hole scavenger (triethanolamine) to the electrolyte, the current density of $\mathrm{CuO}_{\mathrm{F} 1} / \mathrm{CN}$ can be further increased to $225 \mu \mathrm{A} \mathrm{cm}^{-2}$ at $1.23 \mathrm{~V}$ vs. RHE (Supplementary Fig. 18). Besides, $\mathrm{CuO}_{\mathrm{F} 1} / \mathrm{CN}$ composite electrodes show a lower onset potential $(0.14 \mathrm{~V}$ vs. $\mathrm{RHE})$ in comparison to pristine $\mathrm{CN}$ electrodes $\left(0.38 \mathrm{~V}\right.$ vs. RHE). The faradaic efficiency of $\mathrm{CuO}_{\mathrm{F} 1} / \mathrm{CN}$ electrodes for oxygen evolution reaction is found to be $40.3 \%$ at $1.23 \mathrm{~V}$ vs. RHE (Supplementary Fig. 19).

Overall, the magnitude of the photocurrent correlates well with the results of steady-state fluorescence measurements-the lower fluorescence intensity, the higher the photocurrent (Supplementary Fig. 20). To compare the LTRAS method to other growth strategies of $\mathrm{CuO}$ on $\mathrm{CN}$, we followed two other strategies to synthesize $\mathrm{Cu}$ doped $\mathrm{CN}$ : photodeposition (Supplementary Figs. 21-23) and co-polymerization (Supplementary Fig. 25). All as-prepared electrodes yielded much lower photocurrent densities than those prepared with the LTRAS method (Supplementary Figs. 24 and 26).
The LTRAS-synthesized $\mathrm{CuO} / \mathrm{CN}$ composite electrodes show enhanced absorption and a slight red shift in comparison to the pristine $\mathrm{CN}$ electrodes (Fig. 5e). According to the UV-visible spectra, composite electrodes absorb photons with wavelengths $<420 \mathrm{~nm}$ stronger compared to the bare $\mathrm{CN}$ electrode, indicating the synergistic effect of $\mathrm{CuO}$ and $\mathrm{CN}$. The absorption at wavelengths $>420 \mathrm{~nm}$ is mainly caused by the narrow bandgap of $\mathrm{CuO}$. Enhanced absorption in the blue $(455 \mathrm{~nm})$ can be observed even though the $\mathrm{CuO}$ layer is ultrathin $(<100 \mathrm{~nm})$. The IPCE values of $\mathrm{CuO}_{\mathrm{F} 1} / \mathrm{CN}$ at $415 \mathrm{~nm}$ and $455 \mathrm{~nm}$ reach up to $11.46 \%$ and $3.41 \%$, respectively, which is much higher than pristine CN with only $1.58 \%$ at $415 \mathrm{~nm}$ and $0.29 \%$ at $455 \mathrm{~nm}$ (Fig. 5f and Supplementary Fig. 27). The redshift of the IPCE onset wavelength suggests that the $\mathrm{CuO}$ functions as an absorber in the composite electrodes.

The potential of the photoelectrodes under constant current $(50 \mu \mathrm{A})$ shows a prompt response to light irradiation and shifts to more negative regions in all cases, suggesting a decrease of 
a
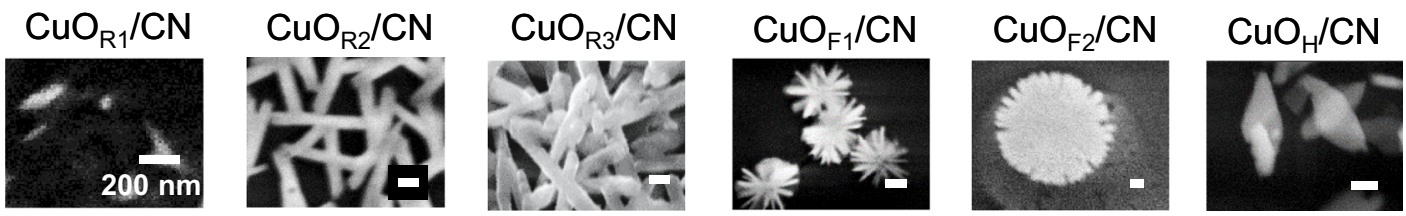

b

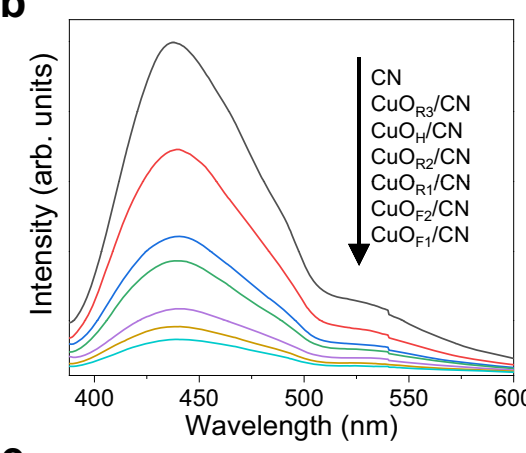

e

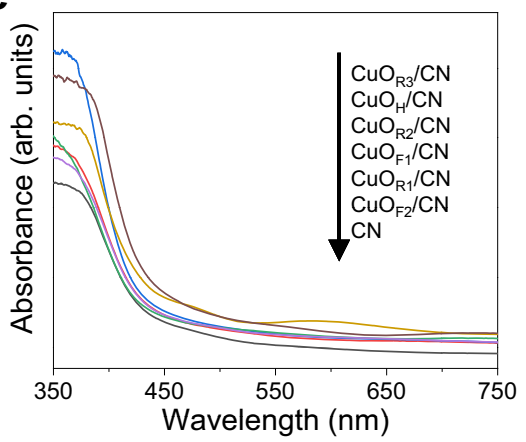

C

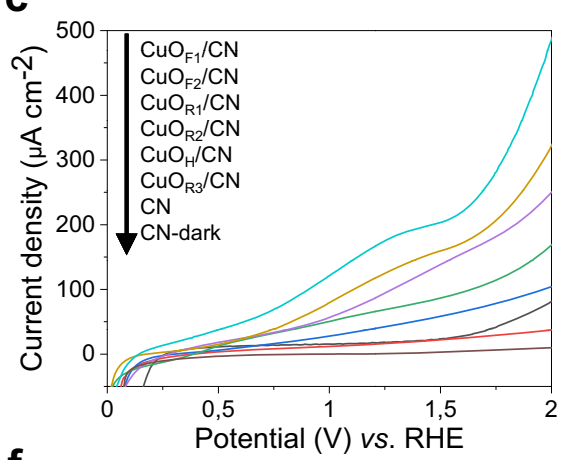

f

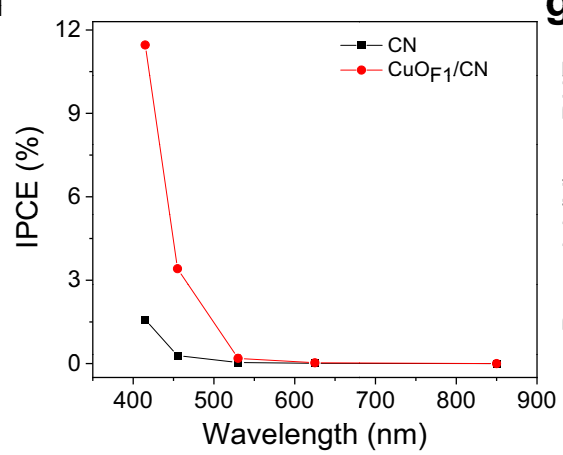

d
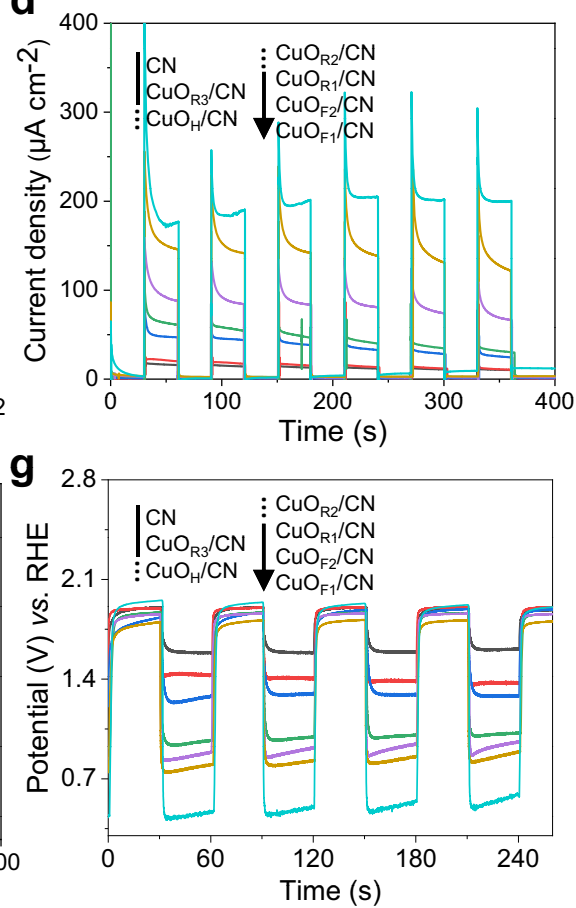

Fig. 5 Photoelectric performance of carbon nitride (CN) and composite electrodes. a Different structures of composite films and their corresponding name. b Photoluminescence spectra. c Linear sweep voltammetry curves under white light. d Transient photocurrent response of CN-based electrodes in $0.1 \mathrm{M} \mathrm{NaOH}$ solution at $1.23 \mathrm{~V}$ vs. RHE (reversible hydrogen electrode) under white light. e UV-visible absorption spectra. f Incident photon-to-electron

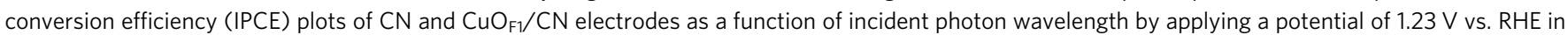
$0.1 \mathrm{M} \mathrm{NaOH}$, and (g) chronopotentiometry under white light.

electrode resistance (Fig. 5g). The composite electrode with the star-shaped structures $\mathrm{CuO}_{\mathrm{F} 1}$ gives the largest drop of resistance under light irradiation. Even under blue light irradiation, the potential of the $\mathrm{CuO}_{\mathrm{F} 1} / \mathrm{CN}$ electrode can be lowered to $0.1-0.2 \mathrm{~V}$ vs. $\mathrm{Ag} / \mathrm{AgCl}$, to achieve the same current as for the pristine $\mathrm{CN}$ electrode at $0.9 \mathrm{~V}$ (Supplementary Fig. 28). Therefore, this electrode can be applied for low-power sensing with advanced performance. For instance, we used a $\mathrm{CuO}_{\mathrm{F} 1} / \mathrm{CN}$ electrode as a photoanode for the detection of glucose. In general, $0.3-0.7 \mathrm{~V}$ vs. $\mathrm{Ag} / \mathrm{AgCl}$ operation potential is necessary to register the response of an electrode to glucose (Supplementary Table 3). However, in our case, $0.1 \mathrm{~V}$ can be sufficient for the $\mathrm{CuO}_{\mathrm{F} 1} / \mathrm{CN}$ photoelectrode according to the results of chronopotentiometry, while the remaining energy demand is supplied via irradiation with light (Supplementary Fig. 29).

Formation of micro p-n junctions in polymer reactor. The significantly enhanced photoelectric properties are induced by the special design of the composite structure upon addition of $\mathrm{CuO}$. By plotting $(\alpha h v)^{2}$ as a function of $h v$ (Supplementary Fig. 30a), the band gaps of the $\mathrm{CN}$ and $\mathrm{CuO}$ were calculated to be $2.74 \mathrm{eV}$ and $1.41 \mathrm{eV}$ respectively, which are in accordance with the onset of absorption. Since the flat band potential can be calculated by the intercept of the tangent in the Mott Schottky (MS) plots with the $X$-axis, we could estimate the valence band edge of $\mathrm{CuO}$ and conduction band edge of $\mathrm{CN}$ with a potential difference of around
$0.1 \mathrm{eV}$ in respect to the flat band potential (Supplementary Fig. $30 \mathrm{~b}, \mathrm{c})^{49}$. Composite $\mathrm{CuO}_{\mathrm{F} 1} / \mathrm{CN}$ electrodes exhibit an inverted V-shape MS plot (Supplementary Fig. 30d), suggesting both the $\mathrm{n}$ - and p-type semiconductors are in contact with the electrolyte. More importantly, this inverted V-shape MS plot confirms the presence of $\mathrm{p}-\mathrm{n}$ junctions ${ }^{49}$.

Based on these results, a band structure is proposed for $\mathrm{CN}$, $\mathrm{CuO}$, and the composite $\mathrm{CuO}_{\mathrm{F} 1} / \mathrm{CN}$ electrodes (Fig. 6a, b). Due to the Fermi level alignment, the band edge of $\mathrm{CN}$ shifts downwards, while that of $\mathrm{CuO}$ shifts upwards ${ }^{49,50}$. Therefore, the conduction band of $\mathrm{CN}$ is more positive in comparison to $\mathrm{CuO}$, which leads to the transfer of photogenerated electrons to the $\mathrm{CN}$, and holes to the $\mathrm{CuO}$. Another factor influencing the charge transfer pathway is the $p-n$ junction. The diffusion and recombination of charge carriers at the interface induce an internal electric field in the depletion region ${ }^{51}$. This electric field forces electrons to move from the p-type $(\mathrm{CuO})$ to the n-type $(\mathrm{CN})$ semiconductor. Hence, the photogenerated electrons and holes in the composite $\mathrm{CuO}_{\mathrm{F} 1}$ / $\mathrm{CN}$ electrodes are spatially isolated, which leads to efficient charge separation.

In contrast, in composite films with multi-layer $\mathrm{CuO}$ structures (such as $\mathrm{Cu}_{\mathrm{OR} 3} / \mathrm{CN}$, Fig. 5a), the photogenerated charges on the outer surface of the $\mathrm{CuO}$ suffer from long-distance diffusion (Fig. 6c). Due to the poor conductivity of $\mathrm{CuO}$, fast recombination occurs before these charge carriers reach the interface between $\mathrm{CuO}$ and $\mathrm{CN}$ (Supplementary Fig. 31). In addition, $\mathrm{CuO}$ 
a

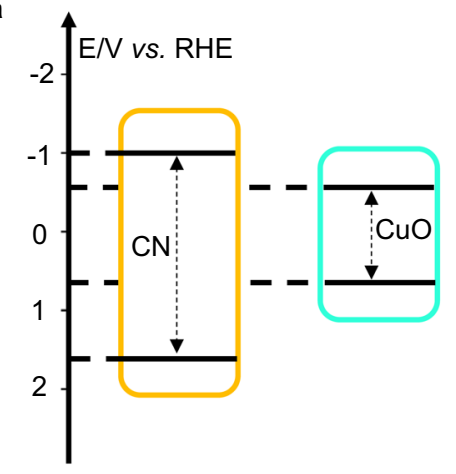

c
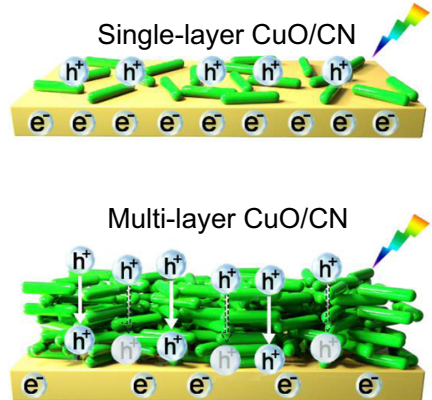

b

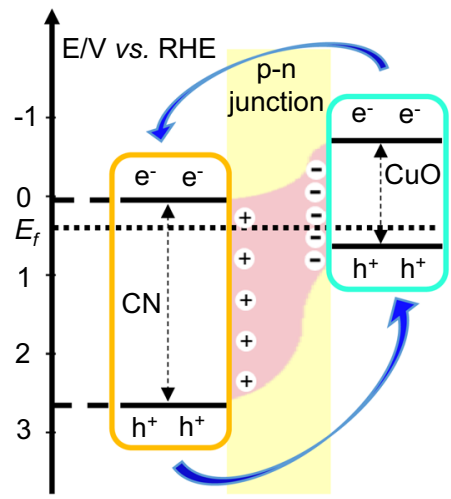

d

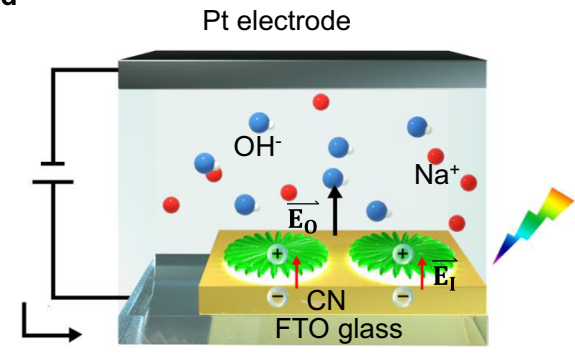

Fig. 6 Energy diagrams of the materials and charge transport properties. a Energy diagram of $\mathrm{CN}$ (carbon nitride) and CuO. b Energy diagram of the $\mathrm{CuO} / \mathrm{CN}$ heterostructure, when $\mathrm{CuO}$ and carbon nitride are in direct contact. c Transport of photogenerated charges in thin-layer and multi-layer $\mathrm{CuO} / \mathrm{CN}$ electrodes. d Star-shaped $\mathrm{CuO}$ on $\mathrm{CN}$ functions as a photoanode under light irradiation and applied potential. RHE reversible hydrogen electrode, $E_{f}$ energy of Fermi-level, $\overrightarrow{\mathbf{E}_{\mathbf{1}}}$ internal electric filed, $\overrightarrow{\mathbf{E}_{\mathbf{o}}}$ applied electric field.

has a high absorption coefficient (e.g., $1.2 \cdot 10^{5} \mathrm{~cm}^{-1}$ at $\left.420 \mathrm{~nm}\right)^{51}$ in the visible range (Supplementary Fig. 32). Applying the Lambert-Beer law, we estimate that a $100 \mathrm{~nm}$ thick layer of $\mathrm{CuO}$ is sufficient to absorb $92 \%$ of the incident light, i.e., only $8 \%$ of incident light reaches the $\mathrm{CN}$ layer. In the case of the thick multilayer $\mathrm{CuO}$, it efficiently blocks the $\mathrm{CN}$ layer located underneath from light. This explains why composite electrodes with a thinner $\mathrm{CuO}$ layer have significantly better photoelectric properties than thicker $\mathrm{CuO}$ structures on the $\mathrm{CN}$. When the composite structures are applied as photoanodes (Fig. 6d), the capacitance of the space-charge region is decreased, resulting in a more efficient flow of charges 7,52 . Therefore, under light irradiation and applied bias potential, micro-scale $\mathrm{p}-\mathrm{n}$ junctions formed in the composite material can strongly improve the charge separation and reduce charge transfer resistance.

Concluding, we introduce the LTRAS method for simultaneous transfer of transition metal precursors and controlled in situ synthesis of defined TMO structures within milliseconds on different substrates, such as glass, FTO, carbon, and CN. For $\mathrm{CuO}$, this method allows control over the size and shape of $\mathrm{CuO}$ nanostructures by careful selection of the laser parameters. The $2 \mathrm{D} \mathrm{CuO}$ assemblies on the surface of $\mathrm{CN}$ form micro-scale $\mathrm{p}-\mathrm{n}$ junctions with an oriented internal electric field. More importantly, thin-layer $\mathrm{CuO}$ can improve the efficiency of charge diffusion and increase the number of photoactive sites in the CN underneath, such that as-prepared composite electrodes possess significantly enhanced photoelectric properties. These composite films can be used for different applications such as low-voltage biosensors for glucose. The photoanode made by deposition of $\mathrm{CuO}_{\mathrm{F} 1} / \mathrm{CN}$ on an FTO substrate shows sensitive current responses upon successive injection of glucose even under 3-6 times lower operation potential than other works. This highly flexible, time-, and energy-efficient LTRAS method can be applied to the synthesis of other TMOs, such as $\mathrm{NiO}$ and $\mathrm{CoO}$ with defined morphologies. This technology provides composite photoanodes with high photocurrent and a facile strategy for the rapid growth of structurally defined TMOs on carbon-based substrates.

\section{Methods}

Four hundred and eighty-eight-nanometer LTRAS machine setup. We use a $200 \mathrm{~mW}$ TOPTICA iBeam smart 488-S laser with a wavelength of $488 \mathrm{~nm}$ (TOPTICA Photonics AG, Germany), that can be flexibly tuned in power and pulse duration. The laser is passed through a 1:10 beam expander, before entering a Racoon 11 laser scanning system (ARGES GmbH, Germany), which is equipped with an f-Theta lens (S4LFT5110/322, Sill Optics GmbH, Germany), as shown for LIFT-based array generation (Supplementary Fig. 3$)^{53}$. This setup allows us to scan the laser focus with a defined speed in a plane of $66 \mathrm{~mm} \times 66 \mathrm{~mm}$, enabling reproducible irradiation of a surface at various positions within the lasing area, with a $1 / \mathrm{e}^{2}$ laser spot diameter of $18 \mu \mathrm{m}$ (Supplementary Fig. 4).

Four hundred and five-nanometer LTRAS machine setup. A second LTRAS setup is equipped with a $405 \mathrm{~nm}$ laser with $100 \mathrm{~mW}$ as shown in Supplementary Fig. 33. Briefly, a commercial laser engraving system was upgraded with a microcontroller, to have full control over pattern, laser power, and laser pulse duration $^{31}$. The laser is attached to two mechanical axes, which move the laser in a plane above the sample surface. The $1 / \mathrm{e}^{2}$ laser spot diameter is $42 \mu \mathrm{m}$ (Supplementary Fig. 4).

Thermal map and profiles. We measured the surface temperatures, which occur during the laser transfer of a single spot ${ }^{46}$. Polyimide donor slides were coated with different long alkanes and irradiated, resulting in a defined melting and evaporation pattern of the alkanes. Since the melting and boiling temperatures are known, we could reconstruct the temperature maps for specific lasing parameters.

In the same setup, a donor slide, coated with $\mathrm{Cu}\left(\mathrm{NO}_{3}\right)_{2}$ embedded in the copolymer, was irradiated with different lasing parameters. Optical microscopy of these irradiation patterns gives the temperature profiles, corresponding to morphological changes (Fig. 3a) induced by different lasing conditions. The morphological changes can be measured and result in an isothermal plot (Fig. 3b). By comparing these values with our previous mappings, the surface temperature profile can be extrapolated. 
Preparation of donor slides. In total, 10,20 or $30 \mathrm{mg} \mathrm{Cu}\left(\mathrm{NO}_{3}\right)_{2} \cdot x \mathrm{H}_{2} \mathrm{O}(99 \%$, Acros) and $30 \mathrm{mg}$ copolymer (S-LEC PLT 7552, Sekisui Chemical GmbH, Germany) were dissolved in the mixture of $50 \mu \mathrm{L} \mathrm{N}, \mathrm{N}$-dimethylformamide, $100 \mu \mathrm{L}$ acetonitrile and $350 \mu \mathrm{L}$ dichloromethane. All solvents were used as obtained from Sigma-Aldrich. We spin-coated the solution on polyimide film (Kapton HN 100 type, Dupont, USA) covered glasses at $80 \mathrm{rps}$. The thickness of the obtained polymer film was measured to be around $1.5 \mu \mathrm{m}$ in vertical scanning interferometry (Supplementary Fig. 34). The obtained slides are the so-called "donor slides". Due to the difference in solubility, $10 \mathrm{mg} \mathrm{Ni}\left(\mathrm{NO}_{3}\right)_{2} \cdot 6 \mathrm{H}_{2} \mathrm{O}(99 \%$, Roth) and $20 \mathrm{mg} \mathrm{Co}\left(\mathrm{NO}_{3}\right)_{2} \cdot 6 \mathrm{H}_{2} \mathrm{O}$ (98\%, Sigma-Aldrich) precursors were used in the preparation of the donor slides for the $\mathrm{NiO}$ and $\mathrm{CoO}$ nanostructures, respectively.

Vertical scanning interferometer. We used a smartWLI compact (Gesellschaft für Bild- und Signalverarbeitung (GBS) $\mathrm{mbH}$, Illmenau, Germany) with low magnification ( $5 \times$ Nikon CF IC Epi Plan DI-Mirau) to show the thickness maps and profiles in large area. The donor slides were partly washed by isopropanol to show the thickness of polymer films after spin-coating. The acceptor slides after laser irradiation were measured directly without further treatment.

Preparation of $\mathbf{C N}$ electrodes. A clean FTO coated glass $(6 \mathrm{~cm} \times 6 \mathrm{~cm}, 7 \Omega / \mathrm{sq}$ Merck) covered a $29.5 \mathrm{~mL}$ rectangular alumina crucible with $5 \mathrm{~g}$ melamine $(99 \%$, Alfa Aesar). We placed the crucible in a furnace (CMF-1200, Carbolite Gero, UK), set to $550^{\circ} \mathrm{C}$, incrementing by $1.5^{\circ} \mathrm{C} \mathrm{m^{-1 }}$, and kept at $550{ }^{\circ} \mathrm{C}$ for $3 \mathrm{~h}$ under nitrogen. The as-prepared slides were cut into small pieces $(1 \times 1.5 \mathrm{~cm})$ and used as $\mathrm{CN}$ electrodes.

Preparation of TMO/CN electrodes. The CN electrodes, as prepared in the previous step, serve as the "acceptor slides" for the laser-assisted generation of TMO/CN electrodes. We placed the donor slides on top of the acceptor slides and loaded them into the sample stage of the laser system. The following laser patterning step was performed either with the $488 \mathrm{~nm}$ or $405 \mathrm{~nm}$ laser LTRAS machine setup. Laser power and processing speed were controlled by the scanning software (ARGES GmbH, Wackersdorf/Bayern, Germany). We used dichloromethane and/or acetone to wash away the remaining copolymer after laser irradiation and the obtained acceptor slides were used as TMO/CN electrodes.

Photoelectrochemical measurements. Transient photocurrent density, linear sweep voltammograms, and chronopotentiometry were measured by a threeelectrode potentiostat (BioLogic MPG2). A Pt electrode (ALS Co., Ltd, Japan), an $\mathrm{Ag} / \mathrm{AgCl}$ on sat. $\mathrm{KCl}$ filling solution (ALS Co., Ltd., Japan), and $0.1 \mathrm{M} \mathrm{NaOH}$ solution are used as the counter electrode, reference electrode, and electrolyte, respectively. The photocurrent with reference to RHE is calculated with the following formula:

$$
E_{(R H E)}=E_{\mathrm{Ag} / \mathrm{AgCl}}+0.059 p H+E_{\mathrm{Ag} / \mathrm{AgCl}}^{0}
$$

where $E_{\mathrm{Ag} / \mathrm{AgCl}}$ is the applied working potential, $E_{\mathrm{Ag} / \mathrm{AgCl}}^{0}=0.1976 \mathrm{~V}$ at $25^{\circ} \mathrm{C}$.

Faradaic efficiency (FE) is measured at $1.23 \mathrm{~V}$ vs. RHE and calculated by the following equation:

$$
F E(\%)=\frac{m \cdot n \cdot F}{I \cdot t} \times 100
$$

where $m$ is the amount of oxygen (mol), $n$ is the number of reaction electrons, $F$ is the Faraday constant, $I$ is the photocurrent (A), and $t$ is the reaction time (s).

Incident photon-to-current conversion efficiency (IPCE) is calculated by the following formula:

$$
\operatorname{IPCE}(\%)=\frac{J_{P h}\left(\mathrm{~A} \cdot \mathrm{cm}^{-2}\right) \times 1240(\mathrm{~V} \cdot \mathrm{nm})}{\lambda(\mathrm{nm}) \times J_{\text {Light }}\left(\mathrm{W} \cdot \mathrm{cm}^{-2}\right)}
$$

where $J_{P h}$ is the photocurrent density, $\lambda$ the wavelength, and $J_{\text {Light }}$ is the intensity of incident light. The flat band potential was calculated using the Mott-Schottky equation $(15 \mathrm{~Hz}$, without light):

$$
\frac{1}{C^{2}}=\frac{2}{N_{D} e \varepsilon \varepsilon_{0}} \cdot\left[\left(V_{S}-V_{f b}\right)-\frac{k_{B} T}{e}\right]
$$

where $C$ is the space-charge capacitance, $V_{S}$ is the applied potential, $V_{f b}$ is the flat band potential, $N_{D}$ is the charge carrier density, $\varepsilon$ is the relative permittivity of the semiconductor, $\varepsilon_{0}$ is the permittivity of the vacuum, $e$ is the elementary charge, and $k_{B}$ is the Boltzmann constant.

\section{Data availability}

Data generated or analyzed during this study are included in this published article and its supplementary information files or are available from the corresponding author on reasonable request.

Received: 3 November 2020; Accepted: 20 April 2021;

Published online: 28 May 2021

\section{References}

1. Qin, J. et al. Direct growth of uniform carbon nitride layers with extended optical absorption towards efficient water-splitting photoanodes. Nat. Commun. 11, 4701 (2020).

2. Shalom, M. et al. Controlled carbon nitride growth on surfaces for hydrogen evolution electrodes. Angew. Chem. Int Ed. 53, 3654-3658 (2014).

3. Barrio, J., Volokh, M. \& Shalom, M. Polymeric carbon nitrides and related metal-free materials for energy and environmental applications. J. Mater. Chem. A 8, 11075-11116 (2020).

4. Kessler, F. K. et al. Functional carbon nitride materials-design strategies for electrochemical devices. Nat. Rev. Mater. 2, 17030 (2017).

5. Karjule, N., Barrio, J., Xing, L. D., Volokh, M. \& Shalom, M. Highly efficient polymeric carbon nitride photoanode with excellent electron diffusion length and hole extraction properties. Nano Lett. 20, 4618-4624 (2020).

6. Lin L., et al. Molecular-level insights on the reactive facet of carbon nitride single crystals photocatalysing overall water splitting. Nat. Catal. (2020).

7. Ye, K. H. et al. Enhancing photoelectrochemical water splitting by combining work function tuning and heterojunction engineering. Nat. Commun. 10, 3687 (2019).

8. Zhao, L. et al. Anchoring $\mathrm{CuO}$ nanoparticles on C, N-codoped G-C3N4 nanosheets from melamine-entrapped MOF gel for high-efficiency oxygen evolution. ChemNanoMat 5, 1170-1175 (2019).

9. Wang, Y. et al. Graphite phase carbon nitride based membrane for selective permeation. Nat. Commun. 10, 8 (2019).

10. Mohamed, H. S. H. et al. In-situ growing mesoporous $\mathrm{CuO} / \mathrm{O}-\mathrm{Doped}$ g-C3N4 nanospheres for highly enhanced lithium storage. ACS Appl Mater. Interfaces 11, 32957-32968 (2019).

11. Wang, J. et al. Direct synthesis of porous nanorod-type graphitic carbon nitride/CuO composite from $\mathrm{Cu}$-melamine supramolecular framework towards enhanced photocatalytic performance. Chem. Asian J. 10, 1276-1280 (2015).

12. Zheng, W. et al. Cu2+-doped carbon nitride/MWCNT as an electrochemical glucose sensor. Electroanalysis 30, 1446-1454 (2018).

13. Fettkenhauer, C., Wang, X. C., Kailasam, K., Antonietti, M. \& Dontsova, D. Synthesis of efficient photocatalysts for water oxidation and dye degradation reactions using CoCl2 eutectics. J. Mater. Chem. A 3, 21227-21232 (2015).

14. Sridharan, K., Kuriakose, T., Philip, R. \& Park, T. J. Transition metal (Fe, Co and $\mathrm{Ni}$ ) oxide nanoparticles grafted graphitic carbon nitrides as efficient optical limiters and recyclable photocatalysts. Appl. Surf. Sci. 308, 139-147 (2014).

15. Sivasankaran, R. P. et al. Influence of $\mathrm{MoS}_{2}$ on activity and stability of carbon nitride in photocatalytic hydrogen production. Catalysts 9, 695-710 (2019).

16. Zhang, Y., Li, K., Liao, J., Wei, X. \& Zhang, L. Microwave-assisted synthesis of graphitic carbon nitride/CuO nanocomposites and the enhancement of catalytic activities in the thermal decomposition of ammonium perchlorate. Appl. Surf. Sci. 499, 143875 (2020).

17. Ngullie, R. C. et al. Synthesis and characterization of efficient $\mathrm{ZnO} / \mathrm{g}-\mathrm{C}(3) \mathrm{N}$ (4)nanocomposites photocatalyst for photocatalytic degradation of methylene blue. Coatings 10, 14 (2020).

18. An, X. Q., Hu, C. Z., Lan, H. C., Liu, H. J. \& Qu, J. H. Strongly coupled metal oxide/reassembled carbon nitride/Co-Pi heterostructures for efficient photoelectrochemical water splitting. ACS Appl Mater. Interfaces 10, 6424-6432 (2018).

19. Liao, C. et al. Constructing conductive interfaces between nickel oxide nanocrystals and polymer carbon nitride for efficient electrocatalytic oxygen evolution reaction. Adv. Funct. Mater. 29, 1904020 (2019).

20. Tan, G. Q. et al. Freestanding three-dimensional core-shell nanoarrays for lithium-ion battery anodes. Nat. Commun. 7, 10 (2016).

21. Sivasakthi, S. \& Gurunathan, K. Graphitic carbon nitride bedecked with $\mathrm{CuO} /$ $\mathrm{ZnO}$ hetero-interface microflower towards high photocatalytic performance. Renew. Energy 159, 786-800 (2020).

22. Chai, B., Peng, T., Mao, J., Li, K. \& Zan, L. Graphitic carbon nitride (gC3N4)-Pt-TiO2 nanocomposite as an efficient photocatalyst for hydrogen production under visible light irradiation. Phys. Chem. Chem. Phys. 14, 16745-16752 (2012).

23. He, L. H. et al. Fabrication of porous $\mathrm{CoOx} / \mathrm{mC} @ \mathrm{MoS}_{2}$ composite loaded on g-C3N4 nanosheets as a highly efficient dual electrocatalyst for oxygen reduction and hydrogen evolution reactions. ACS Sustain. Chem. Eng. 6, 9257-9268 (2018)

24. Zhang, D., Gökce, B. \& Barcikowski, S. Laser synthesis and processing of colloids: fundamentals and applications. Chem. Rev. 117, 3990-4103 (2017).

25. Serra, P. \& Piqué, A. Laser-induced forward transfer: fundamentals and applications. Adv. Mater. Technol. 4, 1800099 (2019).

26. Bohandy, J., Kim, B. F. \& Adrian, F. J. Metal-deposition from a supported metal-film using an excimer laser. J. Appl Phys. 60, 1538-1539 (1986).

27. Pique, A. et al. A novel laser transfer process for direct writing of electronic and sensor materials. Appl. Phys. A 69, S279-S284 (1999). 
28. Ringeisen, B. R. et al. Generation of mesoscopic patterns of viable Escherichia coli by ambient laser transfer. Biomaterials 23, 161-166 (2002).

29. Kattamis N. T., Purnick P. E., Weiss R., Arnold C. B. Thick film laser induced forward transfer for deposition of thermally and mechanically sensitive materials. Appl. Phys. Lett. 91, 171120 (2007).

30. Loeffler, F. F. et al. High-flexibility combinatorial peptide synthesis with laserbased transfer of monomers in solid matrix material. Nat. Commun. 7, 11844 (2016).

31. Eickelmann, S. et al. A low-cost laser-based nano-3D polymer printer for rapid surface patterning and chemical synthesis of peptide and glycan microarrays. Adv. Mater. Technol. 4, 1900503 (2019).

32. Banks D. P. et al. Triazene photopolymer dynamic release layer-assisted femtosecond laser-induced forward transfer with an active carrier substrate. Europhys. Lett. 83 (2008).

33. Hecht L. et al. Blister-actuated LIFT Printing for Multiparametric Functionalization of Paper-like Biosensors. Micromachines 10, 221 (2019).

34. Paris, G. et al. Laser-induced forward transfer of soft material nanolayers with millisecond pulses shows contact-based material deposition. Appl. Surf. Sci. 508, 144973 (2020).

35. Palneedi, H. et al. Laser Irradiation Of Metal Oxide Films And Nanostructures: Applications And Advances. Adv. Mater. 30, 1705148 (2018).

36. Arazoe, $\mathrm{H}$. et al. An autonomous actuator driven by fluctuations in ambient humidity. Nat. Mater. 15, 1084-1089 (2016).

37. Bian, J. et al. Thermal vapor condensation of uniform graphitic carbon nitride films with remarkable photocurrent density for photoelectrochemical applications. Nano Energy 15, 353-361 (2015).

38. Iijima, Y., Niimura, N. \& Hiraoka, K. Prevention of the reduction of $\mathrm{CuO}$ during X-ray photoelectron spectroscopy analysis. Surf. Interface Anal. 24, 193-197 (1996).

39. Gao, J. et al. One-pot synthesis of copper-doped graphitic carbon nitride nanosheet by heating $\mathrm{Cu}$-melamine supramolecular network and its enhanced visible-light-driven photocatalysis. J. Solid State Chem. 228, 60-64 (2015).

40. Bafekry, A., Stampfl, C., Akgenc, B. \& Ghergherehchi, M. Control of $\mathrm{C}_{3} \mathrm{~N}_{4}$ and $\mathrm{C}_{4} \mathrm{~N}_{3}$ carbon nitride nanosheets' electronic and magnetic properties through embedded atoms. Phys. Chem. Chem. Phys. 22, 2249-2261 (2020).

41. Shrestha, K. M., Sorensen, C. M. \& Klabunde, K. J. Synthesis of $\mathrm{CuO}$ nanorods, reduction of $\mathrm{CuO}$ into $\mathrm{Cu}$ nanorods, and diffuse reflectance measurements of $\mathrm{CuO}$ and $\mathrm{Cu}$ nanomaterials in the near infrared region. $J$. Phys. Chem. C 114, 14368-14376 (2010).

42. Cheng, Z., Xu, J., Zhong, H., Chu, X. \& Song, J. Hydrogen peroxide-assisted hydrothermal synthesis of hierarchical $\mathrm{CuO}$ flower-like nanostructures. Mater. Lett. 65, 2047-2050 (2011).

43. Wan, M. et al. Pillow-shaped porous $\mathrm{CuO}$ as anode material for lithium-ion batteries. Inorg. Chem. Commun. 14, 38-41 (2011).

44. Jiang, X., Herricks, T. \& Xia, Y. CuO nanowires can be synthesized by heating copper substrates in air. Nano Lett. 2, 1333-1338 (2002).

45. Chawla, M., Sharma, V. \& Randhawa, J. K. Facile one pot synthesis of $\mathrm{CuO}$ nanostructures and their effect on nonenzymatic glucose biosensing. Electrocatalysis 8, 27-35 (2017).

46. Eickelmann, S., Ronneberger, S., Zhang, J., Paris, G. \& Loeffler, F. F. Alkanes as intelligent surface thermometers: a facile approach to characterize shortlived temperature gradients on the micrometer scale. Adv. Mater. Interfaces $\mathbf{8}$, 2001626 (2021).

47. Pan, J., Liu, G., Lu, G. Q. \& Cheng, H.-M. On the true photoreactivity order of $\{001\},\{010\}$, and $\{101\}$ facets of anatase $\mathrm{TiO}_{2}$ crystals. Angew. Chem. Int. Ed. 50, 2133-2137 (2011).

48. Li, L., Salvador, P. A. \& Rohrer, G. S. Photocatalysts with internal electric fields. Nanoscale 6, 24-42 (2014).

49. Yoo, I.-H., Kalanur, S. S. \& Seo, H. A nanoscale p-n junction photoelectrode consisting of an $\mathrm{NiOx}$ layer on $\mathrm{TiO}_{2} / \mathrm{CdS}$ nanorod coreshell structure for highly efficient solar water splitting. Appl. Catal. B 250, 200-212 (2019).

50. Buscema, M., Groenendijk, D. J., Steele, G. A., van der Zant, H. S. J. \& Castellanos-Gomez, A. Photovoltaic effect in few-layer black phosphorus PN junctions defined by local electrostatic gating. Nat. Commun. 5, 4651 (2014).
51. Sawicka-Chudy, P., Sibiński, M., Wisz, G., Rybak-Wilusz, E. \& Cholewa, M. Numerical analysis and optimization of $\mathrm{Cu}_{2} \mathrm{O} / \mathrm{TiO}_{2}, \mathrm{CuO} / \mathrm{TiO}_{2}$, heterojunction solar cells using SCAPS. J. Phys. 1033, 012002 (2018).

52. Alam, K. M. et al. Enhanced charge separation in g-C3N4-BiOI heterostructures for visible light driven photoelectrochemical water splitting. Nanoscale Adv. 1, 1460-1471 (2019).

53. Mende, M. et al. On-chip neo-glycopeptide synthesis for multivalent glycan presentation. Chem. Eur. J. 26, $9954-9963$ (2020).

\section{Acknowledgements}

This work was supported by funding from the China Scholarship Council, the German Federal Ministry of Education and Research [BMBF, grant number 13XP5050A], and the MPG-FhG cooperation [Glyco3Display]. We thank the Max Planck Society for generous financial support. The authors thank Yuxin Liu for the help with the revised schematics, Gaofeng Chen for fruitful discussions, Markus Antonietti for the support, and Daniel Cruz and Paolo Giusto for assistance with the synthesis of carbon nitride substrates. This work was partly carried out with the support of the Karlsruhe Nano Micro Facility (KNMF, http://www.knmf.kit.edu), a Helmholtz Research Infrastructure at Karlsruhe Institute of Technology (KIT, http://www.kit.edu).

\section{Author contributions}

J.Z. and F.F.L. conceived the idea of the LTRAS method. J.Z. designed, performed, and analyzed the experiments and devised the composite photoanode. S.E. and S.R. performed thermal profiles and supported the LTRAS development. Y.Z. and A.S. helped with the photoelectrochemical measurements and their design. C.N. and T.H. performed XPS and TEM measurements, respectively. F.F.L. supervised the project. The manuscript was co-written by J.Z. and F.F.L., and revised by A.S., V.S., S.E., and P.H.S.

\section{Funding}

Open Access funding enabled and organized by Projekt DEAL.

\section{Competing interests}

The authors declare no competing interests.

\section{Additional information}

Supplementary information The online version contains supplementary material available at https://doi.org/10.1038/s41467-021-23367-7.

Correspondence and requests for materials should be addressed to F.F.L.

Peer review information Nature Communications thanks the anonymous reviewer(s) for their contribution to the peer review of this work.

Reprints and permission information is available at http://www.nature.com/reprints

Publisher's note Springer Nature remains neutral with regard to jurisdictional claims in published maps and institutional affiliations.

Open Access This article is licensed under a Creative Commons Attribution 4.0 International License, which permits use, sharing, adaptation, distribution and reproduction in any medium or format, as long as you give appropriate credit to the original author(s) and the source, provide a link to the Creative Commons license, and indicate if changes were made. The images or other third party material in this article are included in the article's Creative Commons license, unless indicated otherwise in a credit line to the material. If material is not included in the article's Creative Commons license and your intended use is not permitted by statutory regulation or exceeds the permitted use, you will need to obtain permission directly from the copyright holder. To view a copy of this license, visit http://creativecommons.org/ licenses/by/4.0/.

(C) The Author(s) 2021 